\title{
The Experience of Giving Constant Care to a Psychiatric Patient
}

\author{
Olive Yonge
}

The University of Alberta

What is it like to give constant care to a psychiatric patient? It may be argued that a person cannot possibly know unless they have the experience of sitting with a patient who is frightened and dangerous. Constant care involves sensing the patient, passing time with her, and recognizing that she cannot be trusted, while maintaining a safe environment. It is a form of care that gives validation to the nurse as a healer.

In the dark hallway outside of the patient's room, the night nurse who has sat constantly with Joan, gives a quick report, "She tried to kill her baby ... only two months old ... looks like a typical postpartum depression ... apparently is hearing voices ... the devil told her to get a knife ... the baby is on Station 43 ... he's doing fine ... the cuts to his arms and legs were superficial ... Look, if she gets restless give her Largactic $100 \mathrm{mg}$ IM ... I gave the last shot at 0400 hours and it is ordered for every 3 to 4 hours ... get help for the shot ... force fluids if you can, get her to void, she hasn't gone since 1800 hours ... she has been searched but be careful, she might take the comb or whatever to you." As she speaks she flips the pages of the chart, her eyes search for bits of information that might prove helpful to me. When she reaches the lab values at the end of the chart she snaps the chart closed and shoves it into my hand. "That's it. Good luck." She grabs her bag and strides toward the lighted, safe nursing station.

I slip into the room, pause to let my eyes adjust to the dimness. My senses sharpen with my fear of the known and the unknown. I scan the room-it is a private-that means she is very ill. A constant care in a private versus a semi or a 4 -bed usually is a lot more work. Key words from the quick verbal report filter back to me, "voices ... devil ... knife ... be careful." Yet from years of experience, I know that often a report leaves a more negative or stronger impression of a patient than is realized in a face-to-face encounter. The report of the night nurse is influenced by her fatigue, fears, clinical competence and need to leave the patient. Since it sums up in five minutes what has happened over eight hours, it is usually overpowering, and since it comes from one tired nurse, it is also tense.

I slowly, quietly advance to the bed, keeping my eyes on that rounded form under the covers. Reaching the head of the bed, I see a 
young woman, asleep, with large, dark shadows under her eyes. Her face looks drawn and lined and is framed with dirty, limp, tangled curls. Silently I count her breaths and listen to the air escape from her lungs and squeeze through her nostrils. The sleep is regular. Good, the Largactil is still effective. Turning my head, I look for a chair. After finding it I slowly sit down, hoping that the sound of air escaping from the vinyl cushion as it is being compressed won't wake her. I want time to sense her, to know her, and to collect myself.

Here I am, about to encounter another person, to form a healing relationship. How do I do this when all I feel is fear, distrust, confinement and anger? Yes, anger. She cut her child with a knife: she could have killed him. Why didn't she hurt herself instead? Why didn't she ask for help? Why did she have to use this method to get the help she so desperately needs? My guilt rises in me and reaches my brain. I know better. I know about post-partum depression, about a sense of hopelessness and inadequacy, feelings of desperation, despair and fits of violence. I know that under aggression lies the fear of attack. I know that the devil's voice is really a voice created by lack of sleep, imbalanced hormones, feelings of anxiety. I know that she needs to be mothered, nurtured, and cared for.

Moans begin to escape from her lips. "Jasper, Jasper," she calls. She has an accent. Quickly she sits up, moves her arms in large circles and then lies back. Silent. It is like I've watched a movie. I am not ready to acknowledge my presence in this relationship. But where do I begin?

\section{The Experience of (Mis)Trustful Space}

The basis of a therapeutic relationship is trust. When a patient is placed on constant care, he is not trusted. The assumption is that he will harm himself or others. This often angers the patient and he asks, "Don't you trust me?" and the professional answers may be evasive:, "Right now you need the best care we can offer;" confrontive: "You have given me no reason to trust you;" Placating: "Of course, but trust needs to develop;" Honest: "No, right now I don't trust you." There are no right answers in psychiatric nursing, just better ones or more appropriate ones for differing situations. Basically the nurse does not experience trust in the patient and how she conveys this is central to the development of a therapeutic relationship.

What is trust? The dictionary definition is filled with descriptors that apply to constant care: "the firm belief in the honesty, reliability, etc. of another; faith; confident expectation, hope, etc.; responsibility resulting from confidence placed in one; care, custody." The difficulties arise, though, when the nurse wants to care, to hope, to believe in the patient but cannot do so because she does not trust. 
Therefore, the nurse cannot go forward with her care but rather is bound by the chattels of mistrust.

What does this mean? Sadly, the answers are shown in interviews with nurses: "It is like feeding the bears in the zoo." "It is like sitting with a time bomb." At some level, the nurse understands that she cannot really care for this patient when she cannot trust him. She is merely passing time with him until he reaches a trustworthy state. Time means quantitatively spending eight hours and 15 minutes with one ill patient; qualitatively it is measured by feelings and experiences. The nurses describe constant care as "boring," "demanding," "challenging"--descriptors which imply different rates of time passing. The sense of time the nurse experiences may be very different than the sense of time the patient possesses. The nurse or the patient may be "putting in time," "using time," "holding on to time," "forgetting about time," etc., but are they experiencing time in the same way, in the same space? To become a healing force the nurse needs to center on the patient, to try to empathize, to understand his immediate perception of the world, to understand his present sense of time.

\section{The Meaning of Healing}

A broken bone mends through the fusion of cells, but how does a broken heart, or mind, or spirit heal? How does a psychiatric patient get well? Does the answer to this question lie in the medication a patient takes? The safety of the hospital environment? Or even the electroconvulsive therapy? For a patient to receive constant care, the presence of the nurse is validated as a healing force.

Healing of the mind doesn't take place in an orderly, predictable fashion as does healing of the skin or bone. Usually it is a very slow process, often plagued with further tears and scar tissue. It is a visible and invisible process; known and unknown to the patient. As skin heals it may pull tautly across joints and tendons causing pain, and so it is with the mind; new growth may cause new pain.

So how does the nurse promote healing in the patient? In psychiatry she begins by realizing the power she holds in her own body and mind - she doesn't offer the patient a drug or a dressing tray-but herself. She is there to form a therapeutic relationship with the patient, to be helpful and to effect change. When constantly with a patient she is able to create a space filled with power and hope.

The nurse heals through her eyes, touch, voice, gestures, and presence. She communicates through her body: "I care." "You will get well." "Be calm." "Take time for yourself." "I am with you." "You will make it." The patient constantly feels the presence of the nurse, smells her odour and knows the feeling of safety in the experience of illness when with her. 
To be this healing force the nurse must come to work prepared to work. Not only must she be well rested, nourished, and centered on the patient, but also she must be intuitive, mentally flexible, and believe in her own healing powers. She needs to be skilled in assessing changes, minute and gross. She needs to be able to take control and teach her patients how to center on themselves as in teaching them how to relax. She needs to use her experience through reflection, validation and evaluation to improve the quality of healing with each successive patient.

At night coming home, the nurse tells her story: I had to sit constantly with this forty-year-old woman who had just lost control at home. She had taken her kitchen scissors and had cut the living room curtains to shreds, all 30 feet of them. She then tried to rip open the sofa, but by then her husband had called the police and they brought her here.

When I began my shift she was really agitated, probably because of the strangeness of the hospital and the changes in light. She kept her roommate awake and kept pushing at me even though she was tied to her bed. Finally, I gained control of the situation and was able to see that she was very ill, very scared, and out of control. So I began to rub her hands, then her arms, then her back, legs and feet. As I rubbed I sang a lullaby-over and over and over again. In the morning, at the end of my shift, I bathed her and there it was in her eyesgratitude.

\section{The Meaning of Fear}

The patient was tied to the stretcher. He was chanting and yelling. All of a sudden he did a sit-up and bit my nose. The nurse beside me had a brain, thank goodness, and quickly hit him in the throat. He gagged and released my nose.

Safety is never taken for granted in psychiatry. Patients who are tense, mentally disorganized and desperate will also be unpredictable and aggressive. The patient's ability to aggress is a hazard, just as radiation is to a nurse working with patients who have cancer and are being treated with radiation therapy. In nursing, the basic questions about safety are always directed to the nurse: "Can she give safe care?" To have the question redirected back to the nurse, "Can this nurse be kept safe?" is a strange twist. Nurses, especially inexperienced ones, find this frightening. Aggression and nursing were never meant to be bed partners.

To be assigned constant care means this patient was harmful to himself or others, the patient was aggressive. To have constant attention from a nurse may irritate a patient and provoke him into an aggressive state. To have a nurse go into the washroom with a patient who is having a bowel movement, to watch a patient while he 
eats or sleeps may be very frustrating. Depending on the patient's illness, there may be times he may not be aware of the nurse's presence as the nurse invades the patient's privacy. Yet the nurse does not know when these times occur.

A common reaction to aggression is fear. If the nurse has been told that a patient is violent, she will nurse the patient cautiously, nonverbally communicating her unease. The healing forces inside her will be barred as the basic requirement of her own need for safety is met. To compound the problem, the nurse may set up a selffulfilling prophecy such as "This is a violent patient. Watch out." Once the prophecy is established, all patient behaviors are perceived as dangerous and noteworthy.

Being constantly with an ill patient is very difficult, especially when the nurse is continuously frightened by the unpredictability and untrustworthiness of the patient. Nowhere else in society does one receive constant care. Even a newborn baby, completely dependent on a caretaker, has hours where he or she does not need attention or care. The sick child may require a lot of care, but if the nurse is working very hard physically, she is able to relieve her tension and also her sense of time changes; safety and trust are not issues for the nurse since healing may become externalized to medications, fluids and other concrete interventions.

I look at my watch, 1510 hours. Good. I'll soon be relieved by the evening nurse. I've been checking my watch every minute since 1500 hours, or so it seems. I quickly glance outside to check on the weather because very soon I'll be leaving this patient, this room, and this hospital. I hear the knock and look up to see the relief nurse. In a moment I assess her. I am ready to leave, eager in fact, but I also want to leave Joan in "good" hands. At 0700 hours, Joan was a diagnosis of post-partum depression, a warning, "watch out for aggression," but now to me she is a woman, a mother and a wife who is also confused, depressed, anxious and fatigued. Most of her behavior may be understood even if not necessarily appreciated.

During the shift we exchanged the same air, walked in the same space and occasionally touched each other's bodies. Emotionally, we exchanged feelings: she has now less fear and I have more depression. She heightened my awareness of the noisy world outside of the room by becoming agitated every time there was an announcement over the intercom. I began to resent the unwelcome intrusion of outside noise and yet felt powerless to stop it. Throughout the shift she reeked of medication, a smell that is strong, sharp, and chemical-like. It is a smell that will stay with me when I leave the unit.

The report ends, "Don't be scared to touch her. She's only been in Canada for three months and feels very isolated." I turn to Joan, "I'll see you tomorrow morning. I'm glad I'll be with you again." She raises her hand, but her eyes remain closed. 